\title{
La silla coja: la reinserción laboral en mujeres de 45 a 55 años con ruptura conyugal
}

\author{
Arancha Díaz Sáenz \\ Departamento de Filosofía de los Valores y Antropología Social, Euskal Herriko \\ Unibertsitatea / Universidad del País Vasco (UPV/EHU) \\ <arandiaz63@gmail.com>
}

\section{Koldo Salinas Aragón}

Departamento de Filosofía de los Valores y Antropología Social, Euskal Herriko Unibertsitatea / Universidad del País Vasco (UPV/EHU)

<brasilirunen@yahoo.es>

\begin{abstract}
2016ko Bizi Baldintzei buruzko Inkestaren emaitzen arabera, emakumeak dira Espainiako etxe gurasobakarren \% 81,3ko buru eta arrisku handiagoa dute pobrezia gertatzeko. Ikerketa batzuek ongi frogatu duten bezala (Fernández eta Tobío, 1998), oso ohikoa zen 1950. urteen hamarkadaren bukaeran jaiotako emakumeen artean ezkondu ondoren lan ordaindua uztea. Bi emakumeren lekukotasuna jaso du ikerketak, Zaragozakoa eta Donostiakoak dira, eta 54 eta 49 urte dituzte, hurrenez hurren. Azaldu dutenez, erosteko ahalmena eta gizarteharremanak galtzeaz gainera, arazo handiak eduki dituzte lanean berriro hasi ahal izateko. Elkarrizketa sakonak daude bi bizitza-historia hauen oinarrian eta informazio emaileek argiro utzi dute etxean, familia beste eginkizunik gabe, gelditu izanaren balantze negatiboa, eta nabarmendu ere egin nahi izan dituzte ingurukoen esker eskasa eta egoera horrek alaben heziketan eduki duen eragin handia, Legarretak (2008) emaniko denboraz eta Ulrich Beckek (1986) genero-rolek modernitatean izaniko bilakaeraz eginiko ikerketak berretsiz.
\end{abstract}

\section{GAKO-HITZAK:}

Emakumea, dibortzioa, pobrezia, lanean berriro hastea, galera.
Según la Encuesta Continua de Hogares de 2016, el $81,3 \%$ de los hogares monoparentales en España están encabezados por mujeres y son más vulnerables a la pobreza. El presente artículo recoge el testimonio de dos de estas mujeres, el cual evidencia la pérdida de poder adquisitivo y redes sociales tras divorciarse y las dificultades para reincorporarse al mercado laboral. Como era habitual entre las mujeres nacidas a finales de los años cincuenta, nuestras protagonistas abandonaron el trabajo remunerado al casarse. Las dos historias de vida muestran el balance negativo que realizan estas mujeres sobre su dedicación exclusiva al ámbito doméstico y familiar, el insuficiente reconocimiento de su labor por parte del entorno y el efecto de todo ello sobre la educación de sus hijas, corroborando las investigaciones sobre el tiempo donado de Legarreta y la evolución de roles de género en la modernidad de Beck.

\section{Palabras Clave:}

Mujer, divorcio, pobreza, reincorporación laboral, pérdida. 
- Las escasas pensiones alimenticias y las deficientes ayudas sociales son también las causas del empobrecimiento de las mujeres,

\section{Introducción}

En el Estado español, las familias monoparentales, generalmente encabezadas por una mujer, presentan mayor vulnerabilidad y un número en alza. Salvo en el caso de las viudas, el resto de familias 'monomarentales' son negativamente juzgadas moral e ideológicamente. Asistimos, pues, a una contradicción entre el pensamiento político-científico y la vida social.

A partir de los años ochenta, con el debilitamiento de las redes de parentesco y el deterioro del mercado laboral, este tipo de familias pasa a ser una cuestión sociopolítica, tanto a escala estatal como internacional, y pese al cambio que se observa, continúan siendo familias problemáticas y estigmatizadas, autopercibiéndose así también muchos de sus miembros.

Como señala Lefaucher, "las familias monoparentales siguen siendo historias de mujeres" (1988: 156, cit. en Vicente y Royo, 2006). Según el Instituto Nacional de Estadística (2017), en el Estado español ocho de cada diez familias monoparentales $(81,3 \%)$ están encabezadas por una mujer, y sus problemas más frecuentes son la toma de responsabilidades en solitario, las dificultades para conciliar vida laboral y familiar y, en gran medida, los relativos a su situación económica y niveles de bienestar. Cuando estas mujeres quedan solas, sus ingresos económicos se ven reducidos y deben hacer frente en solitario a la esfera productiva y reproductiva.

Según la Encuesta de Pobreza y Desigualdades Sociales (Gobierno Vasco, 2017), las personas más afectadas por la pobreza en Euskadi son las que viven en hogares monoparentales, en un $82,7 \%$ encabezados por una mujer. La tasa de pobreza de las familias monoparentales es del $19 \%$, frente al $7,8 \%$ de las encabezadas por hombres, y como se ve, son las que tendrían mayor necesidad de ayuda.

Entre las causas de la feminización de la pobreza, podemos citar:

- Las desigualdades de género en el ámbito del trabajo remunerado (menores salarios por igual trabajo que el de los hombres, dificultades de acceso a los mismos puestos de trabajo) $\mathrm{y}$, en general, en el ámbito social (menores oportunidades sociales y políticas).

- El abandono de la actividad productiva para centrarse en las tareas que tienen que ver con el cuidado de la familia. En estos casos, reincorporarse al mundo laboral remunerado les resulta sumamente difícil, por el menor reciclaje profesional o la reducción de redes sociales, dándose así una mayor dependencia económica respecto al varón. quienes, en muchos casos, arrastran a sus hijos a la pobreza.

El desempleo es una de las principales causas de la pobreza femenina, pero el empleo no es una garantía contra ella (Rodríguez, 2001, cit. en Vicente y Royo, 2006), puesto que los empleos a los que acceden son los menos cualificados y peor remunerados, a lo que habría que añadir la difícil conciliación de la vida familiar y laboral. Los nichos laborales en los que se localizan estas mujeres son el servicio doméstico, la hostelería y la limpieza, sectores que se caracterizan por la economía sumergida, la inestabilidad, el reducido prestigio social, los bajos salarios y las pocas probabilidades de ascenso, lo que las hace más vulnerables socioeconómicamente. Tener una edad elevada supone un factor de riesgo adicional. Como resultado de todo ello, las mujeres que encabezan familias monoparentales pueden llegar a la pobreza extrema y la exclusión social, arrastrando con ellas a sus hijos/as.

Las familias monoparentales atraviesan, tras la ruptura de la vida conyugal, la viudedad o el abandono, un duelo y un doloroso proceso posterior de reorganización y reestructuración familiar, personal y relacional, con importantes repercusiones económicas.

Desde el punto de vista de las implicaciones económicas de la monoparentalidad, el trabajo remunerado, además de recursos económicos, aporta autoestima e identidad social. Por eso, habría que mejorar las medidas para conciliar vida laboral y familiar, con mayor oferta de servicios de cuidado, seguimiento del cumplimiento de las obligaciones de los padres y aumento de los empleos a tiempo parcial para fomentar la reinsercerción sociolaboral de las mujeres 'monomarentales'. Se necesitan “no sólo políticas de empleo, sino también programas que mejoren sus expectativas, que hagan más atractivo el trabajo remunerado y que faciliten su compatibilidad con las responsabilidades familiares (Rodríguez, 2001: 229; Moreno, 2000: 60; cits. en Vicente y Royo, 2006).

Las dificultades de tipo emocional y económico condicionan frecuentemente la vida de las mujeres tras una ruptura conyugal, y más aún si, como las protagonistas de las historias de vida que se analizan en este artículo (D1 y D2), esas mujeres se sitúan entre los 45 y los 55 años. Las hemos elegido por su indefensión más acusada a causa de la edad. Como era habitual entre las mujeres nacidas a finales de los años cincuenta (Fernández Cordón y Tobío, 1998), nuestras protagonistas abandonaron el trabajo remunerado al casarse, y si ya de por les iba a resulta muy complicado acceder a un empleo acorde con la profesión que ejercían de solteras, debido a su edad lo tienen mucho más complicado. A lo anterior, tendríamos que añadir que la sociedad ve a la mujer 
como 'cuidadora natural'. Por todo ello, sus opciones laborales se limitan a empleos en hostelería que nadie quiere, empleos de atención al cliente, como cajeras o reponedoras de supermercados, y al servicio doméstico, dentro de un contexto de temporalidad (siempre y cuando las admitan como cabezas de familia en un puesto de trabajo).

En los casos que presentamos, las quejas manifestadas van en ese sentido: la imposibilidad de acceder a empleos acordes con los que tenían de solteras; o la falta de oportunidades para reciclarse, debido a sus actuales responsabilidades familiares. Su situación se vuelve más desesperada si cabe. Son absolutamente invisibles y están condenadas, ellas y sus hijos/as, a la pobreza.

El acceso a la vivienda es también fuente de preocupación. En el caso de D1, la mujer de Zaragoza, tiene que recurrir a su familia, volver con sus padres, con todo lo que ello conlleva psicológicamente. En cambio, D2 tiene la 'suerte' de no haber vendido el piso de sus padres; sin embargo, se trata de un piso antiguo y presenta la desventaja de que hay que mantenerlo. Las condiciones sociales de D2, la mujer de Donostia, no son además tan graves, pues cobra una pequeña pensión.

\section{Historia de vida: D1}

D1 se casa y deja su trabajo remunerado para dedicarse al trabajo reproductivo:

En un momento de mi vida, cuando los niños eran pequeños, yo me sumí en mi vida familiar y me daba igual. Y ahí estaba, y no tenía más aspiraciones de... de... de trabajo, y me daba lo mismo haber perdido yo mi condición de decoradora.

Ella se sentía a gusto y conforme en esa función de ama de casa, se sentía realizada en su papel y además consideraba que lo hacía bien:

Yo desarrollaba un papel también importante, que creo que es el mantenimiento de la casa en general... Mis hijos tenían una vida mejor que los que no estaban con su madre.

Yo me sentía realizada con mi vida en casa..., no..., no...0 sea, yo he sido feliz también en casa..., he considerado que mi trabajo estaba bien hecho ahí.

Yo, me daba lo mismo haber perdido yo mi condición de decoradora, entre comillas, mucho más bonita y glamurosa que la que tenía de ama de casa, pero me daba igual, por el bien de mi familia y de él, que pudiera salir al trabajo y no tuviera problemas de niños.

La entrevistada reconocía estar de acuerdo con su papel de ama de casa y que esto la favoreció en la crianza de sus hijos, aunque más adelante reconoce que, cuando se divorció, esto no le aportó nada. Aquí podemos ver la idea de tiempo donado que propone Matxalen Legarreta (2008: 45), “un tiempo que no se vende ni se regala, y que opera en una lógica distinta (no opuesta) a la cuantificación y a la mercantilización".

La conformidad con su papel de ama de casa refleja la influencia de la educación recibida de su madre, que era muy tradicional respecto al papel de una buena ama de casa:

Mi madre, pues bueno, pues chica, si puedes seguir, si puedes vivir sin tener que estar trabajando, la vida es más tranquila, y bueno. Yo he vivido... con una familia muy tradicional, de la generación anterior: la madre, en casa, dedicada a sus labores, que además le gustaban, cosa que a la familia entera nos inculcó.

La informante considera que su circunstancia personal también la ayudó a la hora de estar contenta en casa con su papel reproductivo, ya que tuvo que cuidar a su padre enfermo al principio de su matrimonio, y ambos vivían en el hogar paterno de ella:

Entonces, cuando pillé mi casa, estaba súper emocionada... Por mis circunstancias particulares, la cogí más a gusto y me sentía muy bien dueña y señora. No es que me sintiera ama de casa, es que me sentía como la reina de mi casa.

Dejó de trabajar porque pensaba que era mejor para su matrimonio, y porque, con el sueldo de su marido, podían vivir bien, sin lujos, pero cómodamente:

Dejé de trabajar, pues por tener una vida más cómoda mi familia, y yo... Por el trabajo que tiene, como no..., no..., no creía yo que fuera necesario, pues económicamente íbamos normal. No para vivir en un palacio de Buckingham, pero pues para lo que yo considero vivir bien, pues a gusto.

Al casarse, dejó el trabajo de decoradora, para el que estaba formada, y en el que tenía su clientela y un buen sueldo:

¡Yo soy diplomada! Trabajé para lo que estudié, tenía un buen sueldo en el año 87... Laboralmente, yo me sentía muy reconocida, porque es que había mucha gente que venía a buscarme.

Nunca pensó que se divorciaría:

Una vez que me separo, que por supuesto nunca había pensado que llegase ese eh..., que me llegase a mí. ¡Qué no, qué no! Yo pensé que jamás me iba a separar, porque todo iba, pues dentro de los parámetros normales, de la normalidad de la gente, eh, de..., en fin, bien.

Yo, en principio... dejo el trabajo, porque pienso que, claro, voy a..., voy a estar con mi marido toda la vida. 
Cuando se separa a los 45 años, se le viene el mundo encima y se enfrenta a la cruda realidad; y al estado anímico decaído en que se sume, hay que añadirle la preocupación económica, el qué va a ser de ella y de sus hijos. En un principio, no sabe con qué recursos va a contar:

Empieza una vorágine que se te come la tripa, de “¡socorro! ¿Y ahora qué hago con mi vida?”. ¿Qué hago con mi vida?, ¿qué hago con mis hijos?, ¿qué hago yo? Que... cómo voy a conseguir dinero, no me va a coger nadie [para trabajar], te sientes mayor..., anímicamente fatal, jfatal!

A los 45 años, que es cuando me separo, eh, por supuesto, mi marido se va con su negocio y me deja la casa, que, en eso, la casa me queda con la hipoteca, pero bueno, en un principio, lo veo como bien... Después, ves que la casa tiene su contribución, su tal, su cual, sus gastos, que también tienes que, eh, hacerte cargo tú y que no dejan de ser más gastos con..., con todo lo demás... Para mí, la vida se ha complicado.

Yo no sabía cuánta ayuda, o sea, cuánto me iba a estar pasando de pensión... Yo pensé que me iba a quedar pensión hasta que me jubilara, ¡fíjate qué tontería!... Después te das cuenta [de] que la pensión, en realidad, es por equis años... Hasta que se reincorporan al mundo laboral para los hijos, pero para las mujeres se acaba en cuatro o cinco años.

Es entonces, cuando $\mathrm{D}_{1}$ decide reincorporarse al mundo laboral, cuando se da cuenta de las dificultades que esto supone, por la edad, porque ha perdido el tren laboral durante los años que ha estado casada y no ha ejercido su profesión de decoradora, porque ha perdido relaciones sociales y contactos:

A ver, eh, tuve claro yo también eso [reincorporarse al mundo laboral] cuando te viene encima la realidad... y dices, o sea, he estado veinte años aquí trabajando de ama de casa, que he perdido el tren laboral. Que no me puedo reincorporar...

Ve que los puestos a los que puede acceder son precarios, mal remunerados, y por supuesto, no tienen nada que ver con su formación:

Y claro, tuve que agarrarme a cualquier cosa, hasta me ofrecieron limpiar en hospitales, me ofrecieron ir a reponer en las estanterías de Carrefour... Y yo, sí, decoradora, después de veinte años y habiendo hecho cursos del Inem - que, sí hice-, de AutoCAD..., pero después me veía incapaz de reincorporarme al mundo laboral por miedo, porque llevas muchos años [fuera], porque eres mayor, porque pierdes, por supuesto, facultades.

Fue complicado encontrar empleo incluso en esos puestos que estaban por debajo de su formación:
Por supuesto, por supuesto, me reincorporo a un trabajo en una empresa de comida preparada, pero también llevó la cosa de administración... Para eso, pues también tienes que estar un poco formada hoy en día... Ahora todo lleva un programa informático... En fin, que tienes que estar formada y, cuando ya eres más mayor, eso te cuesta más que cuando lo aprendes a los veinte años.

Al intentar reincorporarse, se da cuenta de que los puestos a los que puede aspirar son precarios y mal remunerados, como dice Beck (1998: 148): “a menudo, las mujeres sólo están 'a un hombre de distancia' de la pobreza".

Estas situaciones la llevan recapacitar sobre la decisión que tomó en su día de dejar el trabajo remunerado para dedicarse a ama de casa:

Yo, a ver, yo con lo que me ha pasado..., a mí, una de las cosas que me ha dado muchísima rabia, y que lo he hecho fatal, y que a mi hija ya le estoy inculcando otra cosa, es que jamás deje de trabajar, jamás. Porque es perder el tren laboral; para mí, ha sido que hoy en día, a mis 54 años, me veo como si yo no hubiera estudiado ni hasta la EGB, cuando resulta que yo tenía una formación académica superior.

También se da cuenta de la pérdida de círculos sociales que supone estar aislada en lo doméstico:

Yo creo que laboralmente se conoce a mucha gente que se mueve en otro, pues eso, en el mundillo [en] que tú trabajas. Si tú trabajas de reponedor en el Carrefour, conoces a los reponedores; si trabajas en un consejo de administración, conoces a los consejeros, que se mueven en otra élite.

Aislarse en lo doméstico le ha supuesto pérdida de relaciones sociales y dificultades a la hora de encontrar un empleo adecuado, y siente que ha perdido el tren laboral. Como señala Rosaldo (1979: 160), "las mujeres son relacionadas con lo doméstico a causa de su rol de madres; esto limita sus actividades económicas y políticas, y sus emociones y atenciones".

La entrevistada reflexiona sobre el trabajo doméstico, que a ella le han inculcado como un deber:

El trabajo de las amas de casa..., que es muy desagradable, muy ingrato, muy injusto, en el sentido de que nadie te lo ve más que sí, que quede más limpio o tal... Es aburrido. Y monótono, y no te aporta nada; ni es creativo, ni nadie te lo reconoce, ni los valores esos que te venden desde fuera [el trabajo remunerado], que bien, o te aplauden, o tienen una aportación económica; en los trabajos de casa, no.

Lo que tampoco pensaba yo es que, por ese trabajo que desarrollé, que nadie me pagó, que sí 
me reconocía mi marido, pero después tampoco aportó nada para mi futuro ni, ni mi sueldo. Ni pensión, ni pensión cuando sea viejica, eh, pues me iba a suponer eso. 0 sea, veinte años trabajando y para nadie, pasando las fregonas para nadie, y ahora, ¿qué?

Ve que ese trabajo que ha realizado como ama de casa no le va a aportar nada en su futuro, sigue teniendo que hacerse cargo de sus hijos, los empleos a los que puede acceder están mal remunerados y depende de la buena voluntad de un hombre que les pase la pensión alimenticia correspondiente a sus vástagos. Como dice Delphy (1985), "el divorcio es una continuación del matrimonio”.

La entrevistada se da cuenta de cómo va a influir esto en su futuro, pues ahora está cotizando en una categoría mínima y los años de ama de casa no cotizan, porque no están remunerados ni reconocidos o compensados de ninguna manera:

Y estos años que llevo ahora en la empresa de alimentación, con un sueldo muy bajo y cuatro horas, porque ni siquiera me cogen seis, entonces, fíjate tú... ¡Qué pensión me va a quedar! Sólo cobro medio sueldo.

Entonces, entre los años que no trabajé cuando estaba de ama de casa, los años ahora que sólo tengo medio trabajo, y un trabajo de una categoría..., pues mínima, o sea, no tengo la categoría que tenía de decoradora...

En referencia a la pérdida de relaciones, también comenta cómo, tras el divorcio, perdió a la familia política y a amistades:

Por un lado, no tienes vida económica, no tienes una vida exterior, que te supone eso, amigos o compañeros de trabajo, donde muchas veces se estructura la vida de mucha gente.

Se pierde la mitad de la rama de la familia, política por lo menos, aunque te lleves bien..., la pierdes, porque es ley de vida.

Los amigos, unos se desmarcan, otros, bueno, te das cuenta que unos no te atienden, otro te da a ti como reparo, socialmente te quedas como una silla coja.

Unos amigos te dicen: "pues vente”. Pero son todo parejas, a mí..., a mí..., me sentía que iba molestando, porque, pues eso, iba sin mi marido.

Económicamente, empezaba a notar lo que para mí suponía un simple aperitivo...: para mí, era un hachazo cada ronda.

Se da cuenta de que ha llegado a una mediana edad, en la que su vida estaba más o menos organizada, y de forma brusca, con el divorcio, todo se desorganiza:
Es cuando, en realidad, se supone que bien, que los hijos ya empiezan a soltarse del nido..., que tendrías que empezar a entrar dentro también de una serenidad..., como por la tranquilidad del piso pagado. Pues no, empieza una vorágine que se te come la tripa de "¡socorro! ¿Y ahora qué hago con mi vida?”. ¿Qué hago con mi vida?, ¿qué hago con mis hijos?, ¿qué hago yo?

Reflexiona sobre cómo le ha influido la educación de su madre, a la que considera machista y nunca ha asumido su divorcio:

Nos han marcado, nos han marcado nuestras madres... Por ejemplo, yo tuve un hándicap con mi madre, que como es muy machista, no asume el divorcio y encima me echa la culpa a mí.

La educación, muchísimo, influye mucho... Te han inculcado mucho esos valores... A mi madre, cuando me dice "iay!, pues...", yo le digo: "te has equivocado". No. Las mujeres tienen que trabajar, o hacer lo que quieran, y ser desde luego independientes económicamente, nunca estar supeditadas.

Por eso, ella le dice a su hija que no pierda la independencia económica:

A mi hija, ya le estoy inculcando otra cosa, es que jamás deje de trabajar. Jamás.

Ya hace tiempo que a mi hija... le estoy diciendo que ijamás!, ¡eh!, dependa de nadie. Ya le digo eso. Y yo, si volviera hacia atrás, no dejaría mi trabajo.

En la actualidad, ha vuelto a vivir a casa de sus padres, y aunque reconoce que le beneficia económicamente, también le ha supuesto una pérdida de libertad. Dice que su principal motivo es cuidar a su madre, que es viuda, mayor y ya empieza a presentar síntomas de demencia:

Yo, a lo mejor, podía haber seguido viviendo en mi casa..., pero el volver a casa de mi madre ha sido por mi madre, por la edad, porque mis hermanos están fuera. Económicamente, me beneficia, pues porque he podido alquilar mi piso, pero va en detrimento mío, porque yo he perdido muchísima libertad.

Condicionada, y a la vez con las obligaciones de los hijos. Porque tengo una madre a la que atender.

A día de hoy, tiene pareja, pero no conviven y no piensa contraer un nuevo matrimonio:

Yo ahora, ya sabes, pues tengo pareja... Él estaría encantado [de] que yo me fuera a vivir con él..., pero es que yo ahora no me quiero casar..., no me quiero ver obligada a nada, a nada... ¿Sabes qué me da miedo? [Que] después las relaciones se 
van deteriorando. Yo creo que el hecho de convivir desgasta, desgasta...; los malos rollos y todo lo malo de la relación, lo complicado, sale en el día a día, cuando te ves las manías... Después de lo que me ha pasado, no tengo ganas de meterme en ese bucle.

Finalmente, la entrevistada dice sentirse utilizada:

Me siento utilizada, porque he dado mis mejores años laborales, que tienes la cabeza mejor para expansionarte, para ir ganando terreno en el mundo laboral y vas ascendiendo. Yo me veo ahí que, claro, no has promocionado, has perdido el tren...Cuando laboralmente me sentía muy reconocida, ¡claro! Estar vendiendo albóndigas, ¡es que me hierven los higadillos!

Me siento utilizada totalmente por mi marido y por la vida.

Yo me siento, de verdad, utilizada totalmente por el sistema, porque he cuidado a mis hijos, no he pedido ni, en fin, no he pedido al Estado nada.

Considera que hoy no dejaría su empleo ni reaccionaría como lo hizo en su momento:

Y ahora, si volviera hacia atrás, no dejaría mi trabajo.

Si retrocediera, para nada, por supuesto, dejaría de trabajar, para nada, para nada.

\section{Historia de vida: D2}

D2 se divorcia y se plantea volver al mundo laboral:

Era necesario, me tuve que poner a trabajar, porque con dos hijos y una pensión de 450 euros debía de hacerlo.

Aquí se ve que ha salido del matrimonio en una situación penosa. Para tres personas, una pensión de 450 euros, no llega para una vida normal (sin grandes lujos). Otro aspecto de interés es que ella se ha hecho cargo de los dos hijos, es decir, se ha trasformado en una familia monoparental.

D2 habla de lo complicado que fue encontrar un empleo:

De soltera, trabajaba en una oficina, en un estudio de arquitectos. Dejé de trabajar cuando me casé, y después de doce años fue cuando me divorcié. Me encontré con dos niños, sin dinero para poder mantener mi domicilio y no encontraba trabajo más que para limpiar casas y [de] reponedora de grandes superficies.

Se observa que sale de casa 'con lo puesto', sin dinero y volviendo a empezar. Menos mal que todavía poseía el piso de sus padres, que no había vendido y le sirvió como base para recomenzar su andadura. Pero se trata de una vivienda antigua y en malas condiciones, con los problemas que esto acarrea.

Estos empleos no tenían nada que ver con su anterior labor dentro de un estudio de arquitectos, "pero era lo único que encontraba”. D2 asiste, pues, a una pérdida de cualificación personal. Sólo encontraba empleo en tareas de limpieza o en puestos de escasa remuneración, posiblemente, con precarias condiciones laborales, en la economía sumergida y de gran inestabilidad.

Las circunstancias la han hecho cambiar:

Pasado el tiempo, no volvería a caer en los mismos errores, nunca dejaría el puesto de trabajo. Además, yo me haría otra reflexión como mujer: se nos tiene que meter en la cabeza que nunca seremos libres si no podemos valernos por nosotras mismas.

El ser humano aprende de sus errores. He aquí la reflexión ante las nuevas circunstancias, cómo se revuelve ante su divorcio y toma conciencia de su error. Desde esta nueva perspectiva, siente que lo más importante es poder elegir libremente el propio destino:

Pensando como pienso ahora y con la experiencia que me ha dado la vida, me encontraría igual de realizada con un trabajo o con otro si hubiera sido yo la que libremente hubiera decidido hacer las cosas.

D2 ve cómo haber dejado de trabajar, por no necesitarlo cuando empezó a construir su familia, deriva, con el paso del tiempo, en una falta de libertad y una dependencia respecto a su marido. Se observa aquí una clara división sexual del trabajo: el marido aporta el dinero a la familia y la mujer 'cuida' de los niños y del marido. En este sentido, coincidimos con (Sen, 1992: 156) cuando apunta que:

Una persona es pobre si carece de recursos para realizar cierto número de actividades, entre las que se incluyen permanecer viva y gozar de una vida saludable, interactuar socialmente (capital social) y adquirir conocimientos, y expresarse y pensar libremente.

La entrevistada habla de independencia económica:

Cuando estás felizmente casada, no piensas. Luego, te das cuenta del tiempo perdido. Entonces, lo primero es poner los pies en el suelo y darme cuenta [de lo] que me había pasado, y de la dependencia del de al lado. Trabajar sola, con los hijos, sin ayudas, para ser una persona realizada económica e independientemente.

D2 viene a decir que, al principio de la vida amorosa, el aspecto económico no se discute. Se vive un estado de enamoramiento. Algunos autores 
consideran que esa falta de recursos propios de las mujeres permiten afirmar que el matrimonio puede contribuir a empobrecer a las mujeres (Bawin, 1988, cit. en Fernández Viguera et al., 1995):

La entrevistada compara su época de estudiante con su situación actual:

Cuando estudiaba, tenía todos los problemas resueltos, por estar en casa de mis padres; $y$ ahora, estoy en la cruda realidad. Los pocos años que han pasado, ha cambiado tanto la vida que te encuentras 'desnuda'.

[Hoy día] me condiciona la responsabilidad de sacar adelante a los dos hijos sola. No te queda más remedio.

He aquí que D2 sólo piensa en sacar adelante a sus hijos, pero de ella no habla, se hace invisible. El tiempo que dispone para dedicarse a ella misma, fuera del ámbito laboral y el cuidado de los hijos, es mínimo o nulo. Su participación social, más allá de la familia, ha pasado a un segundo plano y, poco a poco, va diluyéndose. Queda en el papel de 'cuidadora natural', que ejerce desde que se casó, y muchas veces se reprocha a sí misma su situación:

[Si me casara y divorciara de nuevo], seguramente [sería] muy distinto, porque el poso de la primera ruptura no se va.

D2 está pasando de un 'ilusionante’ primer matrimonio, seguro y de 'hasta que la muerte os separe', a una ruptura, a la quiebra de la estructura mental que ella tenía. De todo esto habla Ulrich Beck (1998).

Respecto a sus amistades, da a entender que ha instalado un 'cordón sanitario' que no permite traspasar a nadie, y señala cómo ha cambiado su actitud tras el divorcio:

Me ven como quiero que ve vean, porque llevo tal careta puesta que no dejo a nadie que entre en intimidad conmigo.

Sí, algunas vienen a 'pasarte la mano por encima del hombro'; otras, a decirte que es normal; pero ayudarte seriamente, casi ninguna.

D2 asiste a la posible división de sus amistades. Ahora está encontrando a amigos/as de verdad, que le ayudan a buscar empleo y le aportan apoyo y sosiego.

A la pregunta de si piensa que podría rehacer su vida, responde:

Después de la experiencia anterior, me haría abogada para poder defenderme, y pensado así, sin fiarme del de al lado. La cuestión es difícil.
[Las mujeres] nos tendríamos que hacer a la idea [de] que no sería malo dejar a los hijos al padre, y nosotras, pasar el fin de semana con ellos.

D2 se queja de la postura tan cómoda del exmarido. En el fondo, está pensando en la 'custodia compartida', en la corresponsabilidad, para que ambos excónyuges compartan las tareas propias de la crianza.

\section{Conclusiones y propuestas}

Una de las cosas que nos llaman la atención es la compleja relación entre la teoría y la práctica, es decir, entre lo que se dice, se afirma, lo que ideológicamente se asevera, y la realidad de las múltiples relaciones sociales, según la posición socioeconómica, la composición étnica o la opción sexual, por ejemplo.

Como decía Ulrich Beck, “quien habla de familia tiene que hablar de dinero y de trabajo; quien habla de matrimonio tiene que hablar de educación, trabajo, reparto de la desigualdad".

De acuerdo con las estadísticas, tanto en la CAV como en otros lugares del Estado español, el número de mujeres que encabezan familias con hijos no cesa de aumentar. Sería el momento de enfrentarse al problema con medidas como:

- Aumentar el número de pisos de acogida para familias 'monomarentales'.

- Un ingreso básico, especie de RGI, para poder compaginar con el salario, normalmente pequeño, para poder salir del estado de pobreza. Dicho ingreso estaría encaminado a la educación de los hijos.

- Mayores facilidades para acceder a un empleo, como rebajas en la cotización a la Seguridad Social, considerar a estas mujeres como un colectivo prioritario y procurar facilitarles puestos con horarios flexibles.

- Potenciación de los cursos de formación y reciclaje para estas mujeres, e impulso a las guarderías y las clases de refuerzo para sus hijos/as.

- Campañas estatales y autonómicas de publicidad institucional que conciencien a la sociedad para que apoye a este tipo de familias.

- Equiparación salarial: a igual trabajo, igual salario con respecto al hombre (OIT, 1951).

En el ámbito legislativo, se han de buscar acuerdos políticos para aliviar esa situación de desamparo. Es hora de que los partidos políticos dejen de tirarse los tratos a la cabeza y pasen de la teoría a los hechos. ¿Cuántas veces hemos oído y leído las promesas de un igualitarismo real que, pasadas las elecciones, quedan en agua de borrajas? 
Las estadísticas lo dicen bien claro: el problema va aumentando. Conceptos como matrimonio, familia y convivencia están en entredicho. Podemos copiar o crear, pero lo que no podemos dejar de hacer es empezar a movernos con celeridad.

La Comisión de la Condición Jurídica y Social de la Mujer de Naciones Unidas (ONU Mujeres, 2017: 12) animaba a llevar a efecto la igualdad de salarios y oportunidades antes mencionada, recomendando, entre otras cosas, "establecer mecanismos para medir el valor de los cuidados y el trabajo doméstico no remunerados a fin de determinar su contribución a la economía nacional.
Todas las iniciativas que hemos planteado, y otras que posiblemente se vayan haciendo, nos llevan a cuestionarnos si las mujeres de la franja de 45 a 55 años podrían salir de ese bucle en que se ha transformado sus vidas y las de sus hijos/as. Esa situación de pobreza, a la que en la mayor parte de los casos están condenadas ellas y sus hijos, las lleva a afrontar el trabajo en las peores condiciones posibles.

Terminamos con una cita de Ulrick Beck (1986): “¿no estaremos viviendo con el desempleo masivo y con la nueva pobreza la llegada de la sociedad de clases, tras la proclamación de su final?". 
BECK, U. (1998): La sociedad del riesgo. Hacia una nueva modernidad, Barcelona, Paidós.

COMISIÓN DE LA CONDICIÓN JURÍDICA Y SOCIAL DE LA MUJER (2017): El empoderamiento económico de la mujer en el cambiante mundo del trabajo, Comisión de la Condición Jurídica y Social de la Mujer. Conclusiones convenidas, ONU Mujeres [<http://www.unwomen.org/-/media/ headquarters/attachments/sections/csw/61/ csw-conclusions-61-sp-web.pdf)].

DELPHY, C. (1985): “Matrimonio y divorcio: el doble atolladero", en DELPHY, C., Por un feminismo materialista. El enemigo principal y otros textos, Barcelona, Les Dones.

FERNÁNDEZ CORDÓN, J. A.; y TOBÍO, C. (1998): “Las familias monoparentales en España”, Revista Española de Investigaciones Sociológicas, $\mathrm{n} 0 \mathrm{83}$, págs. 52-85.

FERNÁNDEZ VIGUERA, B. et al. (1995): Monografía. Género y exclusión social en la monoparentalidad estudios 1, Fundación Foessa.

GOBIERNO VASCO. DEPARTAMENTO DE EMPLEO Y POLÍTICAS SOCIALES. ÓRGANO ESTADÍSTICO ESPECÍFICO (2017): Comunidad Autónoma de Euskadi. Encuesta de Pobreza y Desigualdades Sociales EPDS-2016. Principales resultados, VitoriaGasteiz, Gobierno Vasco [rhttp://www.eustat.
eus/elementos/eleo014100/ti_Encuesta_de_ pobreza_y_desigualdades_sociales_EPDS2016_Principales_resultados_PDF_16MB/ info014126_c.pdfs].

INSTITUTO NACIONAL DE ESTADÍSTICA (2017): Encuesta Continua de Hogares 2016, Madrid, Instituto Nacional de Estadística [rhttp://www.ine.es/ dyngs/INEbase/es/operacion.htm?c=Estadisti ca_C\&cid=1254736176952\&menu=ultiDatos\&i $\mathrm{dp}=1254735572981\rangle]$.

LEGARRETA, M. (2008): "El tiempo donado en el ámbito doméstico. Reflexiones para el análisis del trabajo doméstico y los cuidados", Cuadernos de Relaciones Laborales, ํㅜㄹ, págs. 49-73.

OIT (1951): Convenio sobre la igualdad de remuneración, Ginebra, Organización Internacional del Trabajo.

ROSALDO, M. Z. (1979): “Mujer, cultura y sociedad: una visión teórica”, en HARRIS, O.; y YOUNG, K. (eds.), Antropología y feminismo, Barcelona, Anagrama, págs. 153-180.

SEN, A. K. (1992) Inequality Reexamined, Cambridge, Harvard University Press.

VICENTE, T. L.; y ROYO, R. (2006): Mujeres al frente de familias monoparentales, serie Cuadernos Deusto de Derechos Humanos, no 38, Bilbao, Universidad de Deusto. 